\title{
Invasive mole: a rare cause of postmenopausal bleeding
}

\section{Mamour Guèye*, Mamadou Lamine Cissé, Mame Diarra Ndiaye-Guèye, Magatte Mbaye, Serigne Modou Kane-Guèye, Jean Charles Moreau}

Gynaecologic and Obstetric Clinic, Aristide Le Dantec Teaching Hospital. 1, Avenue Pasteur, POBox 3001, Dakar, Senegal

Received: 7 June 2013

Accepted: 15 June 2013

\author{
*Correspondence: \\ Dr. Mamour Guèye \\ E-mail: mamourmb@yahoo.fr
}

(C) 2013 Guèye $\mathrm{M}$ et al. This is an open-access article distributed under the terms of the Creative Commons Attribution Non-Commercial License, which permits unrestricted non-commercial use, distribution, and reproduction in any medium, provided the original work is properly cited.

\section{ABSTRACT}

Gestational trophoblastic disease (GTD) describes a number of gynaecological tumours that originate in the trophoblast layer, including hydatidiform mole (complete or partial), placental site trophoblastic tumour, choriocarcinoma and invasive mole. Invasive moles are responsible of most cases of localized gestational trophoblastic neoplasia (GTN). Invasive mole is a condition where a molar pregnancy, such as a partial hydatidiform mole or complete hydatidiform mole, invades the wall of the uterus. It is an extremely rare condition. As GTN is not considered in the differential diagnosis of postmenopausal uterine malignancies, its preoperative diagnosis is challenging. We report a case of invasive hydatidiform mole in a postmenopausal woman discovered in a context of postmenopausal bleeding. She underwent hysterectomy and followed up till her beta hCG levels were within normal limits. The patient is in complete remission in the first postoperative year.

Keywords: Post-menopausal, Invasive mole, Gestational Trophoblastic Neoplasia

\section{INTRODUCTION}

Postmenopausal gestational trophoblastic neoplasia (GTN) is extremely rare and its definite pathogenesis is unknown. ${ }^{1}$ Invasive mole is a condition where a molar pregnancy, such as a partial hydatidiform mole or complete hydatidiform mole, invades the wall of the uterus, potentially spreading and metastasizing to other parts of the body. ${ }^{2,3}$ It is an extremely rare condition. As GTN is not considered in the differential diagnosis of postmenopausal uterine malignancies, its preoperative diagnosis is challenging. We report a case of invasive hydatidiform mole in a postmenopausal woman discovered in a context of postmenopausal bleeding. She underwent hysterectomy.

\section{CASE REPORT}

A 51-year-old woman, postmenopausal for 1 year and half was admitted to the gynaecology unit with heavy vaginal bleeding. She was 9 gravida, 9 para. According to the medical history, her last menstrual period was 1 year and half ago. Her parturitions were spontaneous vaginal. The patient had no history of GTN during her reproductive years, postmenopausal bleeding, or hormone therapy. She was sexually active.

Abdominal examination confirmed a large mass arising from the pelvis, reaching about three fingers breadth below the umbilicus. Speculum and vaginal examination confirmed the uterine origin of the bleeding.

Abdominal and pelvic CT showed an enlarged uterus $(141 \mathrm{~mm})$, globular, seat of an active bleeding. There was no evidence of myometrial invasion (Figure 1). Abdominal sonography, posterior- anterior lung X-ray, and thoracic and abdominal tomographic examinations were performed to find possible metastases in lung and liver. No metastatic lesions were found in the examinations performed. It was decided to perform 
hysterectomy because of the persistence of the bleeding and the long time it takes to have histologic data in our country. No positive pelvic or intra abdominal findings were seen in the peri-operative observations. Total abdominal hysterectomy and bilateral salpingooophorectomy were performed. Specimen was sent to the pathology department.

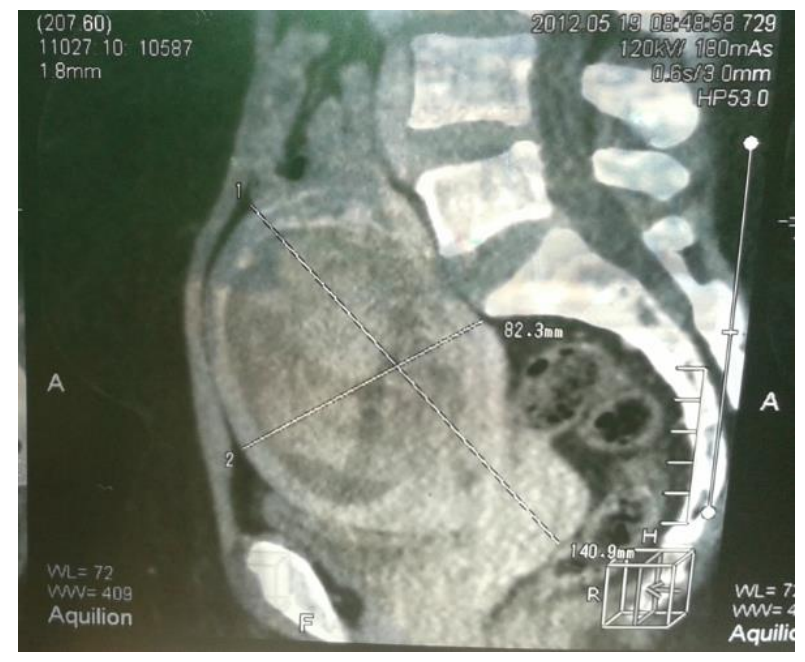

Figure 1: Globular uterus measuring $141 \mathrm{~mm}$ containing a mass with a relatively well-defined margin with active bleeding.

The total abdominal hysterectomy specimen consisted of a $12.8 \mathrm{~cm}$ x $13.1 \times 10.5 \mathrm{~cm}$ uterus with bilateral fallopian tubes and ovaries. Macroscopic examination revealed an enlarged endometrial cavity containing blood clots and hemorrhagic and edematous villi with multiple grapelike transparent vesicles. Microscopic examination of the endometrial tissue specimens revealed generalized hydropic villi with cisterns and circumferential proliferation of trophoblastic cells. The histomorphology findings were consistent with invasive mole.

According to these results, in the postoperative period, the patient was followed by weekly $\beta$-HCG. Initial $\beta$ HCG was $258 \mathrm{U} / \mathrm{ml}$ on postoperative day 28, and decreased to normal range during the 5 th postoperative week. The patient is in complete remission in the first postoperative year.

\section{DISCUSSION}

Gestational trophoblastic disease (GTD) describes a variety of gynaecological tumours originating in the trophoblast layer, including hydatidiform mole (complete or partial), placental site trophoblastic tumour, choriocarcinoma and gestational trophoblastic neoplasia (GTN). Complete and partial hydatidiform moles are non-invasive and account for $80 \%$ of gestational trophoblastic diseases (GTD) cases. Invasive moles that have malignant potential for local invasion and distant metastasis cause most cases of localized GTN. ${ }^{4}$
Some degree of myometrial trophoblastic invasion is probably present in most moles; indeed, myometrial invasion is not exclusive to molar pregnancies. Hertig ${ }^{5}$, borrowing the terminology used for myometrial placentation, classified invasive moles into accreta, increta and percreta. Since hysterectomy is rarely performed in current practice in the treatment of moles, the few specimens seen are usually in unmonitored and often unsuspected pregnancies and, sometimes, are paradoxically percreta moles presenting as acute abdomen due to uterine perforation. ${ }^{6}$

Spontaneous ovulation followed by defective fertilization may be the inciting event in the development of GTN. The pathogenesis of GTNs in postmenopausal women is controversial. In contrast to moles occurring during the reproductive years, postmenopausal GTNs seem to evolve independently of gestation. A latent GTN that remains dormant for long periods and becomes clinically evident in the postmenopausal period is thought to be another mechanism ${ }^{7,8}$ but our patient had a short postmenopausal period, which suggests probable spontaneous ovulation followed by defective fertilization in the development of the invasive mole.

Invasive mole appears histologically benign having a similar appearance to complete molar pregnancy. Despite this appearance, the clinical course of invasive mole is a malignant one, with predominantly invasion of the trophoblastic tissue into the myometrium and spread of molar tissue through pelvic veins. If left untreated, invasive mole can result in heavy bleeding, uterine rupture or other symptoms from local invasion. ${ }^{9,10}$ The presence of villi in the trophoblastic tissue differentiates an invasive mole from choriocarcinoma. ${ }^{6}$

The use of chemotherapeutic agents in invasive mole is controversial. ${ }^{3}$ Although the beta hCG in this case showed a downward trend.

While hysterectomy was performed in the present case with another diagnosis in mind, this is the generally accepted management for women with molar disease in this age group owing to the increased incidence of invasive malignancy.

In conclusion, although gestational trophoblastic disease is extremely rare in postmenopausal women, the diagnosis of hydatidiform mole must be considered when evaluating bleeding in patients who are in postmenopausal period.

\section{REFERENCES}

1. Gilly FN, Cotte E, Brigand C, et al. Quantitative pronostic indices in peritoneal carcinomatosis. EJSO 2006;32:597-601.

2. Atala C, Riedemann R, Biotti M, Ramírez F, Paublo M. Invasive mole with uterine rupture. Rev Chil Obstet Gynecol 1992;57:356-8. 
3. Kittur S, Venktesh RA. A rare case of invasive mole with silent uterine perforation. Int $\mathrm{J}$ Reprod Contracept Obstet Gynecol 2013;2(1):109-10.

4. Soper JT. Gestational trophoblastic disease. Obstet Gynecol 2006; 108:176-187.

5. Hertig, AT. and Mansell, H. Tumours of the female sex organs. Part 1. Hydatidiform mole and choriocarcinoma, in Atlas of Tumour Pathology, 1956; Sect. 9, Fasc. 33, Armed Forces Institute of Pathology, Washington, DC.

6. Kumar S, Vimala N, Mittal S. Invasive Mole Presenting as Acute Haemoperitoneum. JK Science 2004;6(3):159-60.
7. Sato H, Matsuda M, Ikuta M, Hada Y, Kusumoto G, Kirimoto K. Long-dormant invasive mole associated with multiple malignancies. Gynecol Oncol 1985;22:240-3.

8. Taskın S, Cengiz B, Ortac, F. Invasive mole in a postmenopausal woman. Int $\mathbf{J}$ Gynecol Obstet 2006;93:156-7.

9. Martaadisoebrata D. Invasive mole: Indonesian perspective. J Reprod Med 2007;52:839-42.

10. Malhotra B, Misra R. Metastatic invasive mole in the urinary bladder. Indian J Cancer 2002;39:116-8.

DOI: $10.5455 / 2320-1770 . i j r \operatorname{rog} 20130943$

Cite this article as: Guèye M, Cissé ML, NdiayeGuèye MD, Mbaye M, Kane-Guèye SM, Moreau JC. Invasive mole: a rare cause of postmenopausal bleeding. Int J Reprod Contracept Obstet Gynecol 2013;2:451-3. 